\title{
Differential Effects of Lipid and Vitamin D treatment on Cell Viability and CYP24A1 Expression in Hepatocytes and Hepatic Stellate Cells
}

\author{
Zixuan Zhang, James L. Thorne and J. Bernadette Moore \\ School of Food Science and Nutrition, University of Leeds, Leeds, United Kingdom
}

\begin{abstract}
Activated hepatic stellate cells (HSCs) are a key contributor to liver fibrosis and drive the progression to advanced disease for many liver conditions, including non-alcoholic fatty liver disease. Previous studies suggest vitamin D may reduce inflammatory and pro-fi brogenic activity of HSCs in vitro. However, the mechanisms underpinning the effects of vitamin D in HSCs are not fully understood. The overall aim of these experiments was to mimic a lipid loading model on immortalised HSCs to test their responses to 1 $\alpha, 25$-dihydroxyvitamin $\mathrm{D}_{3}\left(1 \alpha, 25(\mathrm{OH})_{2} \mathrm{D}_{3}\right)$. Two different human immortalised cell lines: HepG2, hepatocellular carcinoma cells, and LX-2, hepatic stellate cells; were cultured using standard methods. Cell viability in different treatment vehicles $(2 \%$ DMSO and/or $0.1 \%$ ethanol) under serum free conditions was measured by MTT assay after 6 and $24 \mathrm{~h}$. Cells were cultured with increasing concentrations of fatty acids $(0-500 \mu \mathrm{M}, 1: 1$ oleic acid: palmitic acid) or vitamin D. Nile red, a neutral lipophilic fluorescent dye, was used to measure total intracellular lipid and quantified relative to vehicle. CYP24A1 mRNA expression was measured by qPCR in response to $1000 \mathrm{nM} 1 \alpha, 25(\mathrm{OH})_{2} \mathrm{D}_{3}$ treatment in both cell lines for $24 \mathrm{~h}$ using TaqMan ${ }^{\circledR}$ gene expression assays and normalised to $18 \mathrm{~S}$ rRNA. Cell viability in response to vehicle was examined at $6 \mathrm{~h}$ and $24 \mathrm{~h}$ to determine the optimal experimental time points. Whereas, HepG2 cells remained unaffected at $24 \mathrm{~h}$ in response to either or both vehicles combined $(\mathrm{n}=4$; combined vehicles, $\mathrm{P}=0.3187)$, $\mathrm{LX}-2$ cells showed reduced viability even at $6 \mathrm{~h}(\mathrm{n}=5$; combined vehicles, $\mathrm{P}=0.0050)$. Fatty acid treatment led to intracellular lipid accumulation in both cell lines. In response to $500 \mu \mathrm{M}$ fatty acid treatment, intracellular lipid increased by 1.7 -fold in LX-2 cells at $6 \mathrm{~h}(\mathrm{n}=$ $5, \mathrm{P}=0.00174)$ and 3.9-fold in HepG2 cells after $24 \mathrm{~h}(\mathrm{n}=4, \mathrm{P}=0.00184)$. Notably, CYP24A1 mRNA expression was markedly induced by vitamin D treatment in LX-2 cells $(136 \pm 7.64$-fold, $\mathrm{n}=3, \mathrm{P}=0.0010)$ in comparison to HepG2 cells $(22 \pm 0.78$-fold, $\mathrm{n}$ $=3, \mathrm{P}<0.0001)$. In summary, the cell viability data suggested optimal time points for both fatty acid and vitamin $\mathrm{D}$ treatments may be $6 \mathrm{~h}$ for LX-2 cells, and $24 \mathrm{~h}$ for HepG2 cells. While intracellular lipid accumulation differed between the cell lines in response to fatty acid treatment, both cell lines produced a dose-dependent increase in intracellular lipid. Lastly, CYP24A1 mRNA expression confirmed the responsiveness of both cell types to vitamin D treatment. Ongoing experiments are examining microRNA expression in HSCs in response to both vitamin D and lipid loading.
\end{abstract}

\section{Conflict of Interest}

There is no conflict of interest 